\title{
Genetic evaluations of the German Sport Horse: Population structure and use of data from foal and mare inspections and performance tests of mares
}

\author{
Kati Schöpke, Monika Wensch-Dorendorf and Hermann H. Swalve \\ Institute of Agricultural and Nutritional Sciences, University of Halle, Halle, Germany
}

\begin{abstract}
The aim of the study was to characterize the population of the German Sport Horse, a sub-population of the German Riding Horse, in terms of population structure and genetic parameters. Data from 26490 horses with information from foal inspections ( $F l ; n=17881$ ), broodmare inspections ( $\mathrm{Bl} ; \mathrm{n}=12069)$ and mare performance tests (MPT; $n=2756$ ) from the years 1990-2006 were used for analysis. A total of 21 traits as scored in the three types of performance tests were analysed. Heritability estimates for traits from Fls ranged from $0.24 \pm 0.01$ (conformation) to $0.50 \pm 0.01$ (type). For Bls estimates ranged between $0.15 \pm 0.02$ (forelegs) and $0.50 \pm 0.02$ (head). Traits evaluated in the MPT showed heritabilities between $0.18 \pm 0.02$ (rideability) and $0.46 \pm 0.02$ (trot). Genetic correlations within and across the three tests were all positive. An analysis of the structure of genetic relationships revealed that the population is influenced by different German Riding Horse sub-populations as well as by thoroughbreds. The genetic connectedness within the population is of a complex structure and appeared to be sufficient for genetic analyses. Differences between the genetic parameters estimated in this study for the GSH and those used in the national breeding value estimation system are predominantly insignificant. These results confirm that the GSH is both adequately represented in the national system and that the population itself is a representative part of the entire German Riding Horse population.
\end{abstract}

Keywords: heritability, genetic correlations, conformation traits, young horses performance tests

Corresponding author:

Kati Schöpke; email: kati.schoepke@landw.uni-halle.de

Institute of Agricultural and Nutritional Sciences (IANS), Martin-Luther-University Halle-Wittenberg, Theodor-Lieser-Str. 11, 06120 Halle (Saale), Germany

(c) 2013 by the authors; licensee Leibniz Institute for Farm Animal Biology (FBN), Dummerstorf, Germany. This is an Open Access article distributed under the terms and conditions of the Creative Commons Attribution 3.0 License (http://creativecommons.org/licenses/by/3.0/). 
Abbreviations: BB: Berlin-Brandenburg, BI: broodmare inspection, Fl: foal inspection, GS: genetic similarity, GSH: German Sport Horse, MPT: mare performance test, NSC: number of stallions in common, PEC: pedigree completeness, SN: Saxony, ST: Saxony-Anhalt, TH: Thuringia, vit: Vereinigte Informationssysteme Tierhaltung

\section{Introduction}

In 2010, the breeding stock of German Riding Horses amounted to about 68000 registered mares and 4000 stallions (FN 2010). Of these, approximately 5000 mares and 240 stallions were registered as German Sport Horse (GSH). The GSH is a new horse breed with a common stud book of origin since 2003. It was created by merging the four regional warm-blooded populations of Berlin-Brandenburg, Saxony-Anhalt, Saxony and Thuringia. Horse breeding in these regions is historically closely linked and has developed in close cooperation. The merger of the regional populations and the establishment of a joint breeding programme improved the situation for the breeding organisations with the use of shared resources, providing synergies resulting in a stronger position on the horse market.

The merging of the active breeding populations also leads to a considerably expanded data pool. The GSH is incorporated into the system of integrated breeding value estimation of the German Equestrian Federation, carried out annually by the vit (Vereinigte Informationssysteme Tierhaltung), the central computing centre for genetic evaluations of horses and dairy cattle in Germany. Because the national genetic evaluation system is highly oriented towards sport performance in show jumping and dressage, it was aspired to compare the national system with an internal system focusing on data from foal inspections (FI), broodmare inspections (BI) and mare performance tests (MPT).

The information for the first two data sources is collected at an early stage in the animal's life. It is comprehensively collected with little pre-selection. It focuses on the conformation traits and includes the evaluation of movements presented in hand or free. So far, no genetic analyses had been done on these data for the GSH. However, studies have been undertaken for some of the other sub-populations of the German Riding Horse and the Trakehner breed. Estimates of heritabilities for similar sets of traits showed moderate to high values. As an example, Teegen (2008) found estimates between 0.17 (correctness of legs) and 0.39 (type) for Trakehners. Bösch et al. (2000) reported heritabilities of 0.42 (type/conformation) and 0.40 (gait/swing) for Holsteiner foals. Studies on traits for mare inspections already exist for Holsteiner, Mecklenburger, Trakehner and Hanoverian mares.

Genetic parameters from these studies showed a variation between individual populations as well as between studies. Traits describing the overall type predominantly exhibited high heritabilities. Estimates vary between 0.29 for the Mecklenburger population (Dietl et al. 2004) and 0.46 for Trakehner mares (Teegen 2008). In contrast, for the trait correctness of legs or the individual traits front and hind limbs mostly low heritabilities in the range of $\leq 0.20$ were found (e.g. Bösch et al. 2000, Christmann 1996, Dietl et al. 2004, Teegen 2008). Traits used to describe the quality of movement vary widely in their estimates of heritability (0.09-0.44). This is partly due to different breeding organisations using different definitions for the traits, particularly in earlier studies. In recent years, criteria have become increasingly uniform. Another point is that under some recording systems the environmental influences 
are larger than under others. In general, research has shown low heritabilities for correctness of gaits and a moderate to high heritability for trot.

Mare performance test is focused on the horse's dressage and jumping ability and it is also the interface with the national integrated system for breeding value estimation. A MPT can be conducted as a station or a field test and is harmonized in its trait definitions for the traits walk, trot, canter, rideability and free jumping across Germany. Estimates of the MPT traits as found in other sub-populations of the German Riding Horse are shown in Table 1.

Table 1

Estimated heritabilities for traits in the mare performance test as reported in the literature for various subpopulations of the German Riding Horse

\begin{tabular}{lccclc}
\hline Reference & Walk & Trot & Canter & \multicolumn{1}{c}{ Rideability } & Free jumping \\
\hline Teegen 2008 & 0.23 & 0.47 & 0.22 & 0.19 (test rider) & 0.36 \\
Dietl et al. 2005 & 0.32 & 0.34 & 0.40 & 0.14 & \\
Lührs-Behnke et al. 2002 & 0.27 & 0.38 & 0.34 & 0.29 & 0.54 \\
Bösch et al. 2000 & 0.31 & 0.31 & 0.29 & 0.32 & 0.32 \\
von Velsen-Zerweck 1998 & 0.27 & 0.36 & 0.35 & 0.30 & 0.41 \\
Christmann 1996 & 0.27 & 0.37 & 0.30 & 0.30 & 0.35 \\
Schade 1996 & 0.27 & 0.36 & 0.29 & 0.29 & 0.41 \\
\hline
\end{tabular}

Heritabilities in Table 1 range from 0.23 to 0.32 for walk, from 0.31 to 0.47 for trot, from 0.22 to 0.40 for canter, from 0.14 to 0.32 for rideability and from 0.32 to 0.54 for free jumping. For the integrated breeding value estimation, the vit uses genetic parameters of 0.30 (walk), 0.40 (trot), 0.37 (canter), 0.32 (rideability) and 0.34 (free jumping; vit 2010). German Sport Horses are included in the genetic evaluation. However, no genetic-statistical analyses have been carried out yet specifically for the population of the GSH.

Thorén Hellsten et al. (2006) compared various tests of young horses from European warm-blooded horse breeding associations. They found a good agreement for results of major horse populations. For the Swedish Warmblood, there are two types of 1-day field tests available for young sport horses. For those tests, genetic parameters have been evaluated in several studies (Thorèn Hellsten et al. 2009, Viklund et al. 2008, Wallin et al. 2003). In these studies, the estimates for heritabilities ranged from 0.24 to 0.53 for conformation traits (excepting leg-traits), from 0.17 to 0.53 for gait traits and from 0.17 to 0.33 for jumping traits.

For Dutch Warmblood horses, Ducro et al. (2007) studied the heritabilties of stud book entry traits. In this study, the estimates for the subjective traits were 0.33 for conformation, 0.34 for movement and 0.40 for free-jumping. Koenen et al. (1995) estimated heritabilities for the different linear scored traits for Dutch Warmblood horses. They obtained values between 0.16 and 0.21 (for trait group front), 0.15 and 0.28 (for trait group body), 0.09 and 0.23 (for trait group legs) as well as 0.12 and 0.22 (for trait group movement). Linear conformation traits and type traits have been analysed for the Belgian Warmblood horse by Rustin et al. (2009). The estimates of heritability for this population were between 0.15 and 0.55 for conformation traits and between 0.33 and 0.52 for gait traits. 
The aim of the present study was to characterize the population of the GSH, in particular the population structure and the genetic population parameters. Results from this analysis were regarded as a prerequisite for the development of an internal system of genetic evaluations. Additionally, the analysis was expected to provide information on the question whether the GSH can be regarded as a sub-population of the German Riding Horse and should take part in the national evaluation system. Knowledge about the population parameters and the pedigree structure is also necessary for future research, especially for the development of a system for prediction of genomic breeding values. This study is the first genetic-statistical analysis of the GSH population. It is based on extensively documented performance data and comprehensive pedigree information from the breed associations in Brandenburg-Anhalt and Saxony-Thuringia, which were the partners in this research.

\section{Material and methods}

Data were comprised of Fls and Bls as well as MPTs from 1990 to 2006. Foal inspections take place in the first months of the horse's life and are conducted with the foal walking at foot with the mare. Broodmares are mostly inspected at the age of three years, but may also be inspected at a later age. They are presented in hand or running free. The MPT is designed to evaluate three- and four-year-old mares under rider (gaits and rideability) and free running (free jumping). It can be taken as a one-day field test or as a station performance test lasting 14 to 21 days. All three tests are separate evaluations. Foals were inspected independently from their dams.

Edited data consisted of 26490 animals with records from at least one of the three tests. In total, 1187 mares were examined in all three tests and 3842 passed two tests. The most common combination of two records was FI plus BI (2535 records), followed by BI plus MPT ( $n=1250$ records) and FI plus MPT (57 records). A total of 87199 horses were included in the pedigree file with a maximum of 23 generations. A coefficient for pedigree completeness (PEC) was calculated, using the index proposed by MacCluer et al. (1983). This index describes the proportion of known ancestors for a certain number of generations. It is calculated separately for paternal and maternal lines. The harmonic mean of the paternal and maternal indices explains the overall completeness index for the pedigree of the individual animal. In the present study, the average PEC over 3 generations was 0.99 .

Across all three forms of tests, 21 traits were included in the analysis. All traits were scored on a scale of 1 to 10 with 1 denoting very poor and 10 denoting excellently shown. Use of half-point scores was possible. An overview of the data is given in Table 2.

The number of available records was 17881 for FI, 12069 for BI and 2756 for MPT. Different numbers of observations in $\mathrm{BI}$ were caused by the fact that some of the traits were added subsequently to the evaluation scheme.

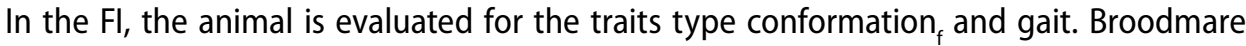
inspections comprise evaluations for seven main traits. The trait conformation ${ }_{m}$ is generated from the arithmetic mean of the individual traits head, neck, saddle position, frame, forelegs and hind legs. Even though type characteristics are closely related to the conformation, the type is judged separately. For scoring type, appearance, proportions and morphological contours are considered. When judging the conformation, certain points of the six individual 
traits are examined. The analysis for MPT concentrated on the traits walk, trot, canter, rideability and free jumping.

Table 2

Raw means $(\overline{\mathrm{x}})$, standard deviation (s), minima and maxima for foal inspection traits, broodmare inspection traits and mare performance tests traits

\begin{tabular}{|c|c|c|c|c|c|c|c|}
\hline & & Trait & $\mathrm{n}$ & $\bar{x}$ & $\mathrm{~s}$ & Min & Max \\
\hline \multirow{2}{*}{$\mathrm{FI}$} & 1 & Type & 17881 & 8.20 & 0.79 & 4.0 & 10.0 \\
\hline & 2 & Conformation $_{f}$ & 17881 & 7.42 & 0.62 & 5.0 & 9.5 \\
\hline \multirow[t]{6}{*}{$n=17881$} & 3 & Gait & 17881 & 7.74 & 0.87 & 4.0 & 10.0 \\
\hline & 1 & Breed and sex type & 12069 & 7.87 & 0.85 & 4.0 & 10.0 \\
\hline & 2 & Conformation $_{\mathrm{m}}$ & 8224 & 7.31 & 0.52 & 4.8 & 9.7 \\
\hline & $2 a$ & Head & 12067 & 7.68 & 0.87 & 4.0 & 10.0 \\
\hline & $2 b$ & Neck & 12069 & 7.64 & 0.84 & 5.0 & 10.0 \\
\hline & $2 c$ & Saddle position & 12068 & 7.66 & 0.82 & 2.0 & 10.0 \\
\hline \multirow[t]{2}{*}{$\mathrm{BI}$} & $2 d$ & Frame & 12069 & 7.40 & 0.84 & 2.0 & 10.0 \\
\hline & $2 e$ & Forelegs & 8228 & 7.03 & 0.70 & 4.0 & 10.0 \\
\hline \multirow[t]{7}{*}{$n=12069$} & $2 f$ & Hindlegs & 9002 & 6.94 & 0.70 & 4.0 & 10.0 \\
\hline & 3 & Correctness of gaits & 12069 & 7.12 & 0.71 & 4.0 & 10.0 \\
\hline & 4 & Walk $_{\mathrm{bi}}$ & 9686 & 7.28 & 0.80 & 4.0 & 10.0 \\
\hline & 5 & Trot $_{b i}$ & 12067 & 7.45 & 0.88 & 4.0 & 10.0 \\
\hline & 6 & Canter $_{\mathrm{bi}}$ & 2162 & 7.28 & 0.71 & 5.0 & 9.5 \\
\hline & 7 & Overall impression \& development & 8045 & 7.52 & 0.76 & 4.0 & 10.0 \\
\hline & 1 & Walk $_{\mathrm{pt}}$ & 2729 & 7.02 & 0.82 & 3.0 & 10.0 \\
\hline \multirow[t]{2}{*}{ MPT } & 2 & Trot $_{\mathrm{pt}}$ & 2728 & 6.81 & 0.82 & 3.5 & 9.2 \\
\hline & 3 & Canter $_{p t}$ & 2729 & 6.90 & 0.78 & 4.0 & 9.5 \\
\hline \multirow[t]{2}{*}{$n=2756$} & 4 & Rideability & 2699 & 6.96 & 0.92 & 3.5 & 9.5 \\
\hline & 5 & Free jumping & 2756 & 7.12 & 0.86 & 3.9 & 10.0 \\
\hline
\end{tabular}

Range of minima for all traits was between 2.0 to 5.0. For the traits saddle position and frame the minimal score was 2.0. For most of the traits the minimal score was 4.0 or 5.0, and thus reflects the insufficient use of the lower part of the scale. The often criticised subjective nature of horse inspections and scoring also leads to a relative low yet typical level of the standard deviation of score values found in data on horse breeding. In this study, data standard deviations were found in the range from 0.62 for conformation fo $_{f} 0.92$ for rideability, without consideration of the cumulative grade for conformation ${ }_{b i}$.

Merging and preparation of data as well as editing was performed using the software package SAS 9.1 (SAS Institute Inc., Cary, NC, USA). The software B\&S Kinghorn Pedigree Viewer (version 5.3, Kinghorn \& Kinghorn 2006) was used for inspections of pedigree links of individual and most influential animals. Merging of performance data files and the pedigree file was done in such a way that only relevant animals were extracted from the pedigree file. 
Relevant animals were defined as animals that either had records or if an animal did not have records, provided more than just one link with another animal. This spruning of the pedigree data was performed using a Python-based programme. The genetic connectedness within the population was checked using genetic similarity (GS) with the help of the genetic similarity formula developed by Rekaya et al. (2003) which was already used by Thorén Hellsten et al. (2008) to measure connectedness among European sport horse populations.

Genetic similarity is calculated from the ratio between the tested progeny of a sire with progeny in different breeding areas and the total number of tested progeny in the respective area [1]. In addition, an imbalance in the distribution of the progeny can be detected when calculating the contribution of each breeding area to the GS [2]. The use of stallions contributing to connectedness served as a further indicator, which was determined by the Number of stallions in common (NSC; used by Thorén Hellsten et al. [2008]). This method is derived from the number of common bulls (Weigel et al. 2000), a measure for genetic connectedness.

$$
\begin{aligned}
& G S_{i j}= \frac{\sum_{k=1}^{N_{i j}}\left(n_{i k}+n_{j k}\right)}{\sum_{k=1}^{N_{i}} n_{i k}+\sum_{k=1}^{N_{j}} n_{j k}} \\
& G S=\frac{\sum_{k=1}^{N_{i}} n_{i k}}{\sum_{k=1}^{N_{i j}}\left(n_{i k}+n_{j k}\right)} \times 100 \text { [in \%] }
\end{aligned}
$$

Where $N_{i j}$ is the number of stallions with tested progeny in region $i$ and $j, n_{i k}$ and $n_{i j}$ are the numbers of tested progeny of stallion $k$ in region $i$ and $j, N_{i}$ is the number of stallions with tested progeny in region $i$ and $N_{j}$ is the number of stallions with tested progeny in region $j$. In the present study, FI data was used to analyse the genetic connectedness. Data from 17881 foals descending from 1329 different stallions was included.

Estimation of variance components were based on the REML-method (Patterson \& Thompson 1971) using the software packages VCE version 5.1 (Kovač \& Groeneveld 2002) and VCE version 6.0 (Groeneveld et al. 2008). The latter was used for the estimation of genetic relationships between traits from BI and MPT. VCE version 5.1 was used for the rest of estimations of variance components. All runs finished with convergence status 1 (i.e. save convergence is guaranteed).

The SAS routine Proc Mixed was used to develop the models by testing the significance of fixed effects and evaluating the AIC-value (Akaike 1973). Estimation of genetic parameters was performed with three different mixed linear models. Traits were assigned to one of the three models below depending on the type of performance test: 
For foal inspection:

$$
\left(F_{I N}\right) y_{i j k l m}=\mu_{i}+\text { age }_{j}+\text { sex }_{k}+\text { place-year }_{l}+\text { animal }_{m}+e_{i j k l m}
$$

where $y_{i j k l m}$ is the phenotypic value of trait $l, \mu_{i}$ is the overall mean, age $e_{j}$ is the fixed effect of age $j$ at performance $(j=1-4)$, sex ${ }_{k}$ is the fixed effect of sex $k(k=1-2)$, place-year, is the fixed effect of combination / of place and year $(l=1-47)$, animal ${ }_{m}$ is the random effect of the foal $m$ $(m=1-17.881)$ and $e_{i j k l m}$ is the random residual effect $\left(0, \sigma_{e}^{2}\right)$.

For broodmare inspection:

$$
\left(B M_{I N}\right) y_{i j k l}=\mu_{i}+a_{j e}+\text { place-year }_{k}+\text { animal }_{l}+e_{i j k l}
$$

where $y_{i j k l}$ is the phenotypic value of trait $l, \mu_{i}$ is the overall mean, age $e_{j}$ is the fixed effect of age $j$ at performance $(j=1-3)$, place-year ${ }_{k}$ is the fixed effect of the combination $k$ of place and year $(\mathrm{k}=1-66)$, animal, is the random effect of the mare $I(I=1-12.069)$ and $e_{i j k l}$ is the random residual effect $\left(0, \sigma_{e}^{2}\right)$.

For mare performance test:

$$
\left(M_{M P T}\right) y_{i j k l m}=\mu_{i}+\text { age }_{j}+\text { type_of_test } t_{k}+\text { place-year-season }+ \text { animal }_{m}+e_{i j k l m}
$$

where $y_{i j k l m}$ is the phenotypic value of trait $l, \mu_{i}$ is the overall mean, age $e_{j}$ is the fixed effect of age $j$ at performance $(j=1-2)$, type_of_test ${ }_{k}$ is the fixed effect of type of test $k(k=1-2)$, placeyear-season, is the fixed effect of the combination / of place, year and season $(l=1-92)$, animal ${ }_{m}$ is the random effect of the mare $m(m=1-2.756)$ and $e_{i j k l m}$ is the random residual effect $\left(0, \sigma_{e}^{2}\right)$.

Overall, it proved to be difficult to define contemporary groups for all three tests. Small test groups are a common problem in equine field data. Small size of groups may cause limited representativeness of the respective group and lead to inadequate connectedness. In this study, alternative definitions of contemporary groups were tested (data not shown) and evaluated, resulting in combinations of place-year and place-year-season which were preferred over the individual test group.

\section{Results}

\section{Population structure}

Parents of horses that completed at least one of the three tests were analysed $(n=26490)$. The results exhibited an average number of 10.8 and 2.0 tested progeny per stallion and mare, respectively. Maximum number of progeny was 616 for sires and 12 for dams. Out of the 2439 stallions, 30 had more than 100, 131 had more than 50 and 583 had more than 10 progeny. Among mares, 29 had at least 10 and 990 had at least 5 tested progeny. An analysis of the stallions with respect to their sub-population of origin showed that $72.8 \%$ of the tested progeny descended from either Hanoverian stallions (18.2\%), Holsteiner (15.7\%), 
Oldenburger (12.4\%) or Westphalians (11.1\%) and $15.4 \%$ could be traced back to GSH. For GSH, the sub-populations of Berlin-Brandenburg (BB), Saxony-Anhalt (ST), Saxony (SN) and Thuringia (TH) contributed 1636, 1264, 739 and 398 stallions, respectively. All stallions of other populations contributed less than five percent of the tested progeny, with the exception of the Trakehner (6\%) and the thoroughbreds (6\%). Dutch stallions were found for $2.4 \%$ of the horses.

Across all four sub-populations of the GSH (BB, ST, SN, TH), 64 common stallions were found (Table 3). In each of the sub-populations, the stallions that also had been used in all other sub-populations amounted to more than $10 \%$ of all stallions of the respective subpopulation. The highest number of common stallions was found for BB and ST ( $n=267)$. The frequency of these sires within the two sub-populations is also comparatively high $(50.3 \%$ and $44.8 \%$ ). The smallest overlap was found between BB and TH with 117 stallions. The contribution of these sires amounted to a relative frequency of $22.0 \%$ and $26.8 \%$.

The NSC in the GSH sub-populations was determined by dividing the stallions into groups based on their birth year (Figure 1). Across all areas, this value ranges between four (19811985) and 20 (1986-1990). The increase in NSC from group I and II (1970-1985) to the following groups (from 1986) indicates a clear increase in the common use of stallions between all subpopulation combinations. Genetic similarity across all four sub-populations is 0.19 . It is based on the 3432 foals of the 64 stallions with tested progeny in all sub-populations. The individual combinations have a GS that ranges from 0.26 (BB-TH) to 0.67 (BB-ST). The contributions to GS demonstrate that the distribution of progeny of the common stallions between the subpopulations is equal (Table 4). The maximum difference is $18 \%$ for the combination TH-SN.

Table 3

Number of stallions in common, proportion of common stallions relative to all stallions in the region and number of progeny of the common stallions with tested progeny in foal inspection $(n=17881)$

\begin{tabular}{lccc}
\hline Region & NSC & $\begin{array}{c}\text { Proportion of common } \\
\text { stallions [\%] }\end{array}$ & $\begin{array}{c}\text { Total number of progeny of } \\
\text { common stallions }\end{array}$ \\
\hline BB - ST - SN - TH & 64 & $12.1-10.7-11.1-14.7$ & 3432 \\
BB - ST & 267 & $50.3-44.8$ & 6011 \\
BB - SN & 208 & $39.2-26.0$ & 4204 \\
BB - TH & 117 & $22.0-26.8$ & 2011 \\
ST - SN & 212 & $35.6-36.7$ & 4217 \\
ST - TH & 155 & $26.0-35.6$ & 3300 \\
SN - TH & 195 & $33.8-44.7$ & 5366 \\
\hline
\end{tabular}

BB: Berlin-Brandenburg, SN: Saxony, ST: Saxony-Anhalt, TH: Thuringia 


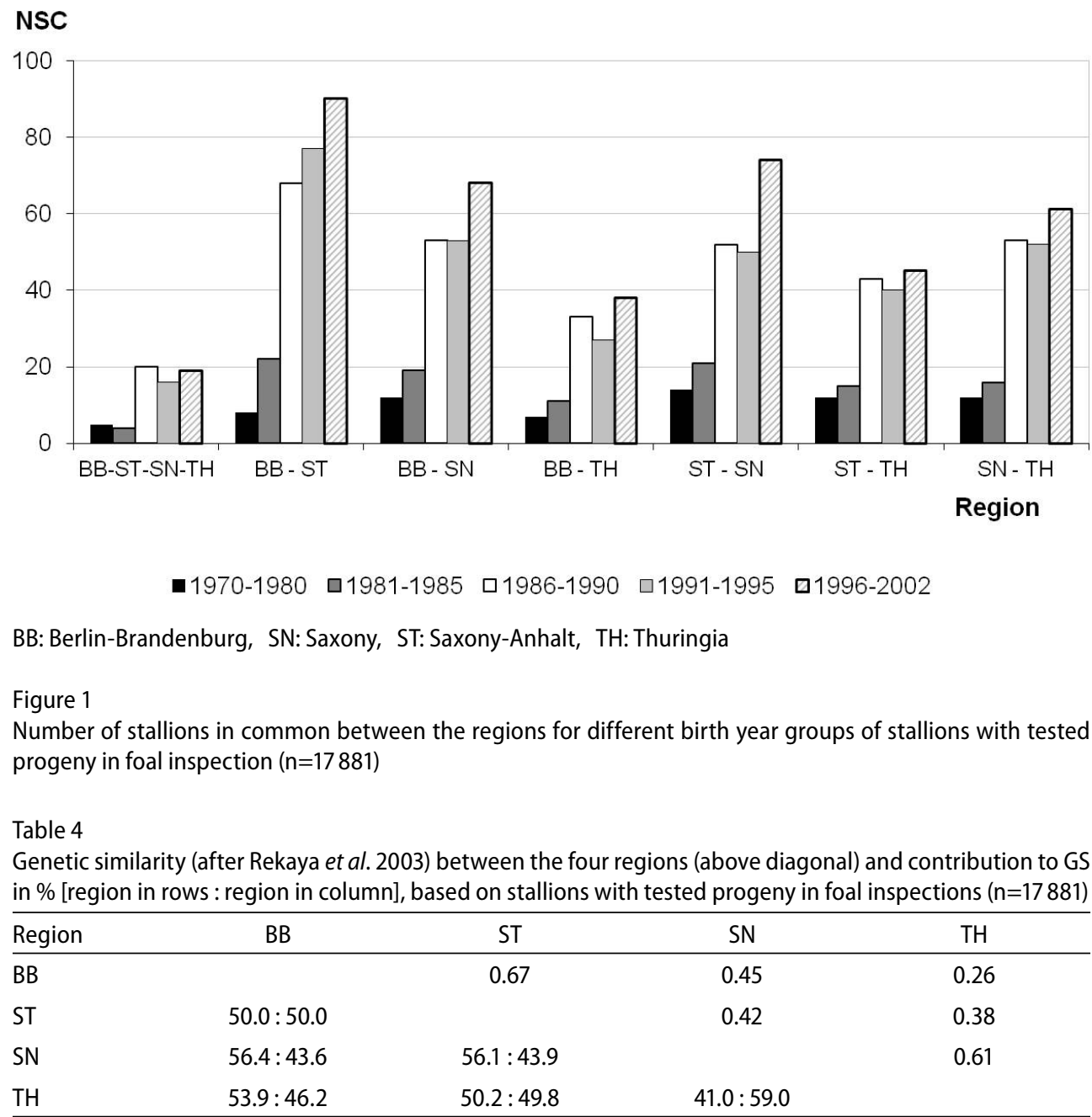

BB: Berlin-Brandenburg, SN: Saxony, ST: Saxony-Anhalt, TH: Thuringia

\section{Genetic parameters}

\section{Foal and broodmare inspection}

Multivariate estimation of variance components for the foal inspection traits resulted in estimated heritabilities of $h^{2}=0.24$ for conformation to $_{\mathrm{f}} \mathrm{h}^{2}=0.50$ for type (Table 5 ). The genetic correlation between type and conformation $n_{f}$ is high $\left(r_{g}=0.84\right)$. Trait combinations type - gait and conformation $n_{f}$ gait show an equal genetic correlation of $r_{g}=0.56$. Genetic relationships between traits from $\mathrm{Fl}$ and traits from BI as well as from MPT were estimated in bivariate runs. Estimates range from moderate to high (Table 6), except for the combination gait - free jumping, which has a low estimate of $r_{g}=0.09$. With the exception of walk $\left(r_{g}=0.48\right), B I$ traits show high genetic correlation with the $\mathrm{Fl}$ traits $\left(0.69 \leq \mathrm{r}_{\mathrm{g}} \leq 0.85\right)$. Individual traits for basic gaits from the MPT range in their genetic correlation to gait from $r_{g}=0.37\left(\right.$ trot $\left._{p t}\right)$ to $r_{g}=0.46\left(\right.$ walk $\left._{p t}\right)$. 
Genetic analysis for BI included 13 traits. Parameters were estimated in bivariate runs. Resulting estimates for correlations are shown in Table 7. Estimates for heritabilities were averaged over all runs. The estimates demonstrate a wide interval for heritabilities of the BI traits. As expected, type $\left(h^{2}=0.46\right)$, conformation ${ }_{m}\left(h^{2}=0.43\right)$ and head $\left(h^{2}=0.50\right)$ exhibit all a high heritability. The conformation traits head, neck, saddle position and frame show a moderate level of heritability. Forelegs and hind legs proved to have low heritability with estimates of $h^{2}=0.15$ and $h^{2}=0.19$. The results for basic gaits range between $h^{2}=0.25\left(\right.$ walk $\left._{b i}\right)$ and $\mathrm{h}^{2}=0.49$ (canter ${ }_{\mathrm{bi}}$ ). Genetic correlations are consistently on a moderate to high level. In particular, the traits type conformation ${ }_{b i}$ as well as overall impression and development are very closely related.

\section{Mare performance test}

Results from multivariate estimation of variance components MPT traits are shown in Table 8. Estimates of heritability vary between $h^{2}=0.18$ (rideability) and $h^{2}=0.46\left(\right.$ trot $\left._{p t}\right)$. Estimates for basic gaits are on a moderate level and thus emphasize the potential for improvements through genetic selection. Among all traits of the MPT, with the exception of free jumping, all genetic correlations are moderate to high.

\section{Genetic relationships between traits from different tests}

The combined analysis of traits from the Bl and MPT gives insight into the genetic relationships between traits from both tests. Results in Table 9 are based on bivariate estimation runs. Estimates of heritability were pooled across bivariate estimation runs. Pooled estimates deviate slightly from those shown in Tables 7 and 8 due to different combinations of traits. For walk and trot, estimates of heritability from MPT were found to be higher by 0.05 than compared to Bl. However, canter shows a considerably lower heritability. Genetic correlations between basic gaits within the two tests range in intervals of $0.50 \leq r_{g} \leq 0.65$ (for BI) and $0.56 \leq r_{g} \leq 0.80$ (for MPT). When comparing the two forms of tests, the respective basic gait traits show a genetic correlation of $r_{g}=0.95$ (walk), $r_{g}=0.69$ (trot) and $r_{g}=0.83$ (canter). It is interesting to note that genetic correlations between free jumping from the MPT and the basic gait traits of BI are higher than those within MPT.

Table 5

Estimates of heritability (on diagonal), genetic correlations (above diagonal) and phenotypic correlations (below diagonal) for foal inspection traits; standard errors in parentheses

\begin{tabular}{llll}
\hline Trait $(\mathrm{n}=17881)$ & Type & Conformation $_{\mathrm{f}}$ & Gait \\
\hline Type & $0.50(0.01)$ & $0.84(0.01)$ & $0.56(0.01)$ \\
Conformation $_{\mathrm{f}}$ & 0.16 & $0.24(0.01)$ & $0.56(0.02)$ \\
Gait & 0.15 & 0.08 & $0.41(0.01)$ \\
\hline
\end{tabular}


Table 6

Estimates of genetic correlations between foal inspection traits and broodmare inspection traits as well as between foal inspection traits and mare performance tests traits, standard errors: 0.015-0.049

\begin{tabular}{llc}
\hline Foal inspection traits & Broodmare inspection traits & Genetic correlation \\
\hline Type & Breed and sex type & 0.85 \\
Conformation & Conformation $_{\mathrm{bi}}$ & 0.82 \\
Gait & Walk $_{\mathrm{bi}}$ & 0.48 \\
Gait & Trot $_{\mathrm{bi}}$ & 0.77 \\
Gait & Canter $_{\mathrm{bi}}$ & 0.69 \\
\hline Foal inspection traits & Mare performance tests traits $_{\mathrm{pt}}$ & Genetic correlation \\
\hline Gait & Walk $_{\mathrm{pt}}$ & 0.46 \\
Gait & Trot $_{\mathrm{pt}}$ & 0.37 \\
Gait & Canter $_{\mathrm{pt}}$ & 0.45 \\
Gait & Free jumping & 0.09 \\
\hline
\end{tabular}

Table 7

Estimates of heritabilities (on diagonal), genetic correlations (above diagonal) and phenotypic correlations (below diagonal) for broodmare inspection traits; standard errors in parentheses

\begin{tabular}{|c|c|c|c|c|c|c|c|c|c|c|c|c|c|c|}
\hline Trait & & (1) & (2) & (3) & (4) & (5) & (6) & (7) & (8) & (9) & (10) & (11) & (12) & (13) \\
\hline $\mathrm{N}$ & & 13562 & 8837 & 135601 & 13562 & 135601 & 13561 & 8848 & 9760 & 13560 & 10783 & 13559 & 2192 & 9060 \\
\hline $\begin{array}{l}\text { Breed and } \\
\text { sex type }\end{array}$ & (1) & $\begin{array}{l}.46 \\
(.02)\end{array}$ & .95 & .86 & .83 & .81 & .83 & .58 & .71 & .76 & .51 & .71 & .72 & .98 \\
\hline $\begin{array}{l}\text { Confor- } \\
\text { mation }_{\mathrm{m}}\end{array}$ & (2) & .29 & $\begin{array}{c}.43 \\
(.02)\end{array}$ & .83 & .81 & .81 & .86 & .67 & .80 & .85 & .58 & .75 & .66 & .98 \\
\hline Head & (3) & .40 & .26 & $\begin{array}{l}.50 \\
(.02)\end{array}$ & .69 & .59 & .61 & .39 & .57 & .65 & .34 & .55 & .46 & .77 \\
\hline Neck & (4) & .34 & .25 & .29 & $\begin{array}{l}.36 \\
(.02)\end{array}$ & .64 & .62 & .44 & .56 & .65 & .39 & .67 & .51 & .80 \\
\hline $\begin{array}{l}\text { Saddle } \\
\text { position }\end{array}$ & (5) & .26 & .22 & .15 & .20 & $\begin{array}{l}.28 \\
(.02)\end{array}$ & .78 & .45 & .60 & .58 & .55 & .67 & .59 & .80 \\
\hline Frame & (6) & .30 & .25 & .19 & .20 & .21 & $\begin{array}{l}.25 \\
(.02)\end{array}$ & .62 & .75 & .70 & .56 & .74 & .74 & .92 \\
\hline Forelegs & (7) & .18 & .18 & .10 & .11 & .12 & .15 & $\begin{array}{l}.15 \\
(.01)\end{array}$ & .73 & .78 & .48 & .52 & .35 & .71 \\
\hline Hindlegs & (8) & .20 & .19 & .14 & .13 & .11 & .18 & .15 & $\begin{array}{l}.19 \\
(.02)\end{array}$ & .81 & .49 & .67 & .48 & .79 \\
\hline $\begin{array}{l}\text { Correctness } \\
\text { of gaits }\end{array}$ & (9) & .17 & .13 & .13 & .12 & .10 & .13 & .15 & .14 & $\begin{array}{l}.16 \\
(.01)\end{array}$ & .45 & .59 & .42 & .71 \\
\hline Walk $_{b i}$ & (10) & .16 & .12 & .09 & .09 & .12 & .13 & .12 & .11 & .09 & $\begin{array}{c}.25 \\
(.02)\end{array}$ & .61 & .50 & .60 \\
\hline Trot $_{b i}$ & (11) & .26 & .17 & .18 & .19 & .19 & .21 & .13 & .13 & .16 & .20 & $\begin{array}{l}.42 \\
(.02)\end{array}$ & .65 & .79 \\
\hline Canter $_{\text {bi }}$ & (12) & .26 & .16 & .13 & .16 & .20 & .21 & .11 & .11 & .11 & .17 & .34 & $\begin{array}{l}.49 \\
(.04)\end{array}$ & .75 \\
\hline $\begin{array}{l}\text { Overall } \\
\text { impression \& } \\
\text { development }\end{array}$ & (13) & .42 & .25 & .30 & .28 & .23 & .31 & .17 & .19 & .18 & .18 & .29 & .28 & $\begin{array}{l}.36 \\
(.02)\end{array}$ \\
\hline
\end{tabular}


Table 8

Estimates of heritabilities (diagonal), genetic correlations (above diagonal) and phenotypic correlations (below diagonal) for mare performance tests traits; standard errors in parentheses; standard errors (s.e.) for genetic correlations: $0.024 \leq$ s.e. $\leq 0.059$ )

\begin{tabular}{llllcc}
\hline Trait & Walk $_{\mathrm{pt}}$ & Trot $_{\mathrm{pt}}$ & Canter $_{\mathrm{pt}}$ & Rideability & Free jumping \\
$\mathrm{N}$ & 2729 & 2728 & 2729 & 2699 & 2756 \\
\hline Walk $_{\mathrm{pt}}$ & $0.29(0.02)$ & 0.55 & 0.62 & 0.37 & 0.03 \\
Trot $_{\mathrm{pt}}$ & 0.28 & $0.46(0.02)$ & 0.80 & 0.66 & 0.08 \\
Canter $_{\mathrm{pt}}$ & 0.24 & 0.37 & $0.28(0.02)$ & 0.73 & 0.22 \\
Rideability & 0.21 & 0.27 & 0.31 & $0.18(0.02)$ & 0.08 \\
Free jumping & 0.09 & 0.12 & 0.16 & 0.13 & $0.41(0.02)$ \\
\hline
\end{tabular}

Table 9

Estimates of heritabilities (on diagonal), genetic correlations (above diagonal) and phenotypic correlations (below diagonal) for broodmare inspection traits (BI) and mare performance tests traits (MPT); standard errors in parentheses; standard errors (s.e.) for genetic correlations: $0.029 \leq$ s.e. $\leq 0.087$ )

\begin{tabular}{|c|c|c|c|c|c|c|c|c|c|}
\hline \multicolumn{2}{|l|}{ Trait } & Walk $_{\mathrm{bi}}$ & $\operatorname{Trot}_{\mathrm{bi}}$ & Canter $_{\text {bi }}$ & Walk $_{p t}$ & Trot $_{p t}$ & Canter $_{p t}$ & Rideability & $\begin{array}{c}\text { Free } \\
\text { jumping }\end{array}$ \\
\hline & $\mathrm{BI}$ & $\mathrm{BI}$ & $\mathrm{BI}$ & MPT & MPT & MPT & MPT & MPT \\
\hline $\mathrm{N}$ & & 9686 & 12067 & 2162 & 2729 & 2728 & 2729 & 2699 & 2756 \\
\hline Walk $_{b i}$ & $\mathrm{BI}$ & $\begin{array}{c}0.25 \\
(0.02)\end{array}$ & 0.61 & 0.50 & 0.95 & 0.55 & 0.62 & 0.50 & 0.05 \\
\hline Trot $_{b i}$ & $\mathrm{BI}$ & 0.20 & $\begin{array}{c}0.41 \\
(0.02)\end{array}$ & 0.65 & 0.60 & 0.69 & 0.71 & 0.53 & 0.18 \\
\hline Canter $_{b i}$ & $\mathrm{BI}$ & 0.17 & 0.34 & $\begin{array}{c}0.48 \\
(0.04)\end{array}$ & 0.44 & 0.51 & 0.83 & 0.52 & 0.50 \\
\hline Walk $_{p t}$ & MPT & 0.22 & 0.13 & 0.12 & $\begin{array}{c}0.30 \\
(0.03)\end{array}$ & 0.56 & 0.65 & 0.38 & 0.03 \\
\hline Trot $_{p t}$ & MPT & 0.12 & 0.22 & 0.22 & 0.28 & $\begin{array}{c}0.46 \\
(0.03)\end{array}$ & 0.80 & 0.65 & 0.08 \\
\hline Canter $_{p t}$ & MPT & 0.10 & 0.18 & 0.28 & 0.24 & 0.37 & $\begin{array}{c}0.28 \\
(0.03)\end{array}$ & 0.73 & 0.17 \\
\hline Rideability & MPT & 0.06 & 0.09 & 0.15 & 0.21 & 0.27 & 0.31 & $\begin{array}{c}0.18 \\
(0.03)\end{array}$ & 0.07 \\
\hline $\begin{array}{l}\text { Free } \\
\text { jumping }\end{array}$ & MPT & 0.06 & 0.07 & 0.13 & 0.09 & 0.12 & 0.16 & 0.13 & $\begin{array}{c}0.41 \\
(0.03)\end{array}$ \\
\hline
\end{tabular}

\section{Discussion}

The GSH is a relatively new sub-population of the German Riding Horse and itself can be stratified into four regional sub-populations. The analysis presented in this study is the first joint genetic analysis of all four sub-populations and covered an analysis of the population structure as well as an estimation of genetic parameters based on data from Fls, Bls and MPTs. The general breeding programme of the GSH is defined as spure-breeding in an open populations. This strategy is reflected in the structure of the parental generation. Of 
all tested horses, $15 \%$ descend from stallions of the regional sub-populations (BB, ST, SN, $\mathrm{TH})$. The population is also considerably influenced by Hanoverian, Holsteiner, Oldenburger and Westphalian stallions. All in all, an intensive use of sires from different German breeding areas was observed. This has a considerable influence on the genetic make-up of the GSH population and also ensures a genetic connectedness with the all-German Riding Horse population. Hence, the genetic connectedness of the GSH with the rest of the German Riding Horse population in the national genetic evaluation system is fully established. The GSH population is a representative part of the German Riding Horse population and therefore will be able to contribute valuable data for future research work concerning genomic breeding values and genomic selection.

Data presented in this study show a gender-specific parents-progeny-distribution typical for horse breeding. The genetic connectedness between the four sub-populations is realized solely by the comprehensive use of sires while the maternal side with its low numbers of progeny per mare contributes little to connectedness. The genetic connectedness between the sub-populations is very strong. The NSC as well as the GS reflect an intensive cooperation between the sub-populations of BB and $\mathrm{ST}$ as well as $\mathrm{SN}$ and $\mathrm{TH}$. The number of common sires across all regions appears to be rather low $(n=64)$. Only a few overall >link-providers could be detected. Even highly frequented stallions are often underrepresented in one of the sub-populations. The percentage contributions of the individual GS according to formula [2] were fairly even and suggest a mostly balanced distribution of the sires and their progeny across sub-populations. Across time, a continuous exchange of genetic material is observed. The enormous increase of the parameter number of stallions in common in the mid-eighties (Figure 1) apparently can be attributed to enhanced opportunities in reproductive biology, especially to the increased use of artificial insemination. Thorén Hellsten et al. (2008) also detected an increasing NSC for Hanoverian and Holsteiner sport horse populations. Between these populations, GS was estimated at $15 \%$.

Germany is the main exporting country for stallions and their genetics in Europe and together with France and the Netherlands, it is considered the most connected country, i.e. population (Ruhlmann et al. 2009). Studies by Thorén Hellsten et al. (2008) show GS values of $0.07 \leq \mathrm{GS} \leq 0.31$ for different European riding horse populations. The horses in this study are connected much closer $(0.26 \leq \mathrm{GS} \leq 0.67)$, which was to be expected since the GSH was formed from closely cooperating sub-populations. The high degree of genetic connectedness is beneficial for an internal system of genetic evaluations as a supplement to the national genetic evaluation system. In summary, the genetic connectedness within the GSH population is not fully balanced. However, it can be considered to be sufficiently strong and complex to enable a reliable estimation of population parameters and breeding values.

The inspection of a foal within the first months of its life provides early indicators of performance for the horse. These data provide a relatively general description of the disposition of the young horse in the traits type, conformation and gait. As expected, the estimation of parameters thus results in a high level of heritability (Table 5). Comparisons with findings of similar studies show values to be predominantly comparable, but the definition of traits is not completely consistent. For Holsteiner foals Bösch et al. (2000) determined values of $\mathrm{h}_{\text {type/conformation }}^{2}=0.42$ and $\mathrm{h}_{\text {gait/swing }}^{2}=0.40$. Teegen (2008) calculated $\mathrm{h}_{\text {type }}^{2}=0.39$ and $\mathrm{h}_{\text {body/legs }}^{2}=0.27 / 0.17$ for Trakehner foals with a sire-dam model. 
The importance of the $\mathrm{Fl}$ as an early indicator was examined using the correlation between traits from Fl and subsequent trait evaluations in the BI and MPTs. Foal inspection as an early performance appraisal has to be viewed from different perspectives. Traits within the trait group type and conformation exhibit high correlations. The genetic relationship between gait (from FI) and walk from both BI and MPT was very similar $(0.48,0.46)$. However, the correlation between gait and the other two basic gaits differs substantially. For trot as well as for canter the genetic relationship between foal and mare traits is much higher for BI than for MPT. It may be hypothesized that one reason for this is the different kind of presentation of the horse. For FI and $\mathrm{BI}$ the presentation of the animals is very similar: free moving or shown in hand. In contrast, for MPT the mare is presented under saddle and is therefore subject to the direct influence of the rider. Since $\mathrm{Fl}$ and $\mathrm{BI}$ are separate evaluations, they are independently judged. Whether the appearance of the mare has an indirect influence on the scoring of the foal cannot be assessed.

Based on the results of this study, the foal evaluation may be considered as a reliable indicator for type and conformation of subsequent tests. With regard to the adult performance in basic gaits, a distinction must be made between the kind of test (BI or MPT). Inferences on the ability in free jumping based on the Fls are not possible.

Estimated heritabilities of the traits in $\mathrm{Bl}$ are within the range of values from other studies for German Riding Horse populations. In particular, for the traits breed and sex type, walk $_{\mathrm{m}^{\prime}}$ trot $_{m}$ and overall impression, the results of this study are almost identical to the values from Teegen (2008) for Trakehner mares. Estimates for forelegs and hind legs as well as the correctness of gaits confirm the apparent low level of heritability, which was also documented for the mare population of Hanoverians (Christmann 1996), Holsteiners (Bösch et al. 2000) and Mecklenburgers (Dietl et al. 2004).

Estimates of heritabilities for further conformation traits as well as the genetic correlations among them were slightly above the values of comparable analyses. Estimates of genetic correlations were somewhat higher for most of the traits when compared to studies by Christmann (1996) and Dietl et al. (2004). However, the estimates almost invariably confirm the trait-specific trend. Very high correlations were found between the characteristics type conformation $_{\mathrm{m}^{\prime}}$ overall impression and development. This finding seems to confirm the existence of suspected autocorrelations between individual traits as presumed by Willms et al. (1999).

A strong genetic relationship between fore- and hind legs with correctness of gaits is documented in correlations of $r_{g}=0.81$ and $r_{g}=0.78$. Considering basic gait traits, genetic relationships appear to be stronger between trot and canter as well as between trot and walk than between canter and walk. Christmann (1996) also found some correlations for BI traits of Hanoverians to be negative. This cannot be confirmed neither for the Mecklenburger population (Dietl et al. 2004) nor from the results of this study.

Viklund et al. (2008) analysed the Swedish Warmblood Horses using data from the Young Horse Test (predominantly 3-year-olds) and from the Riding Horse Quality Test (predominantly 4-year-olds). For the young horse test, these authors found heritability estimates of $0.46 / 0.39$ for type, $0.08 / 0.08$ for correctness of gaits, $0.37 / 0.31$ for walk in hand, and $0.45 / 0.41$ for trot in hand. For the riding horse quality test, the authors also studied the basic gaits under rider and estimated heritabilities of 0.38 (walk), 0.48 (trot) and 0.38 (canter). Analogous to this study, the presentation of walk and trot under saddle in the analysis by Viklund et al. (2008) 
tended to show higher estimates than free-walking or in hand presentation. However, the results of this study show the opposite trend for canter.

Overall, estimates of heritabilities for traits from MPT range within values reported in comparable studies from other German Riding Horse populations (Table 1). Free jumping and trot show high heritabilities. Rideability ranks in the lower range of similar analyses. Huizinga et al. (1990), however, found much lower values $\left(h^{2}=0.03\right)$ for the Dutch population and furthermore, also for other traits evaluated in field tests relatively low values were estimated (trot: 0.14 , walk: 0.22 , canter: 0.18 , free jumping: 0.15 ).

A comparison of the results of this study with the parameters used for the national evaluation system show an almost identical value for walk. For trot and free jumping our estimates are slightly higher than those from the national system. For canter and rideability, the situation is reversed with the highest difference for rideability. A comparison of the genetic correlations estimated in this study with genetic correlations as used for respective traits in the national genetic evaluation system exhibits values and relations between traits largely in a similar range. With the exception of walk : rideability $(\Delta=0.19)$ and trot : canter $(\Delta=0.11)$ the maximum difference is $10 \%$.

Thus, with regard to the national breeding value estimation, the parameters used in the national system appear to be in line with the GSH population. Only the trait rideability should be viewed with a critical eye and the cause of the deviation should be subject to further investigations.

In inspections and performance tests of sport horses as well as when assessing prospects for future success in tournaments, rideability and jumping ability play an important role. Besides show jumping and dressage competitions themselves, the MPT provides an opportunity to assess the dressage and jumping ability of the horse.

However, relatively few mares which often have also been pre-selected participate in the MPT. Thus, the correlations with traits from the Bl, which has a much higher number of participants, are of interest, in particular the basic gaits which are potential link traits. Genetic relationships of traits from $\mathrm{BI}$ and MPT were analysed and the results showed that genetic correlations are on a moderate to high level with the exception of free jumping (Table 9). The three basic gaits are correlated with the respective counterpart with estimates ranging from $r_{g}=0.69$ (trot) to $r_{g}=0.95$ (walk). Teegen (2008) compared results for traits from BI and MPT as a field test. Compared to our study, genetic correlations between BI and MPT as a field test rank equally but on a lower level of magnitude. Christmann (1996) reported higher values with $r_{g}=1.00$ for walk and $r_{g}=0.81$ for trot. It is noteworthy that free jumping in MPT is more closely correlated to basic gaits from the BI than to basic gaits of MPT itself. This may be due to the way the horse is presented. Scoring for basic gaits in MPT is under saddle. Broodmare inspection and free jumping in MPT are conducted with the horse in hand or free walking and consequently there is no effect of the rider in both cases.

The analysis of the relationships between traits across tests proved the inherent connection between Bl and MPT. Genetic correlations between BI and MPT for basic gaits and for rideability allow a joint use of these complexes. However, walk, trot and canter must be considered as individual traits in each test, as they cannot be regarded as an identical trait genetically.

All in all, traits from mare inspection and MPTs have mostly moderate to high heritabilities and do not reveal any genetic antagonisms. This suggests that the prospects for improvements 
through genetic selection are very good. As both tests take place at nearly the same time in the mare's life, the estimation of genetic correlation between the traits of both complexes is not hampered by differences in time. Additionally, close genetic relationships between the respective basic gaits from both tests and the quantity of data from Bls allow a prognosis for the future ability and performance in basic gaits under the rider.

For further research, competition traits should also be considered in the analysis. Studies from Aldridge et al. (2000), Ducro et al. (2007) and Kearsley et al. (2008) have shown that the inclusion of such data is useful since highly positive correlations between competition traits and young horse test traits have been found (Wallin et al. 2003, Viklund et al. 2010).

In conclusion, the data analysed can be considered as suitable for genetic analyses and the estimation of breeding values. A joint use of Fls, Bls and MPTs is a valuable addition to the national system and especially utilizes data from a large number of mares not contained in the sport-oriented national system.

\section{References}

Akaike H (1973) Information Theory and an Extension of the Maximum Likelihood Principle. In: Petrov BN, Csaksi F (eds.) Proceedings of the 2nd International Symposium on Information Theory. Akademiai Kiado, Budapest, Hungary, 267-281

Aldridge LI, Kelleher DL, Reilly M, Brophy PO (2000) Estimation of the genetic correlation between performances at different levels of show jumping competitions in Ireland. J Anim Breed Genet 117, 65-72

Bösch M, Reinecke S, Röhe R, Kalm E (2000) [Genetic analysis for horse breeding traits]. Züchtungskunde 72, 161-171 [in German]

Brockmann A (1998) [Field performance testing of stallions including tournament results]. Doctoral thesis. University Göttingen, Germany [in German]

Christmann $L$ (1996) [Estimation of breeding values for traits from broodmare inspection and mare performance test in Hannover]. Doctoral thesis. University Göttingen, Germany [in German]

Dietl G, Hoffmann S, Albrecht S (2004) [Parameters and trends of mare inspections of Mecklenburger Warmblut Horse]. Arch Tierz 47, 107-117 [in German]

Dietl G, Hoffmann S, Reinsch N (2005) Impact of trainer and judges in the mare performance test of Warmblood Horses. Arch Tierz 48, 113-120

Ducro BJ, Koenen EPC, van Tartwijk JMFM, Bovenhuis H (2007) Genetic relations of movement and freejumping traits with dressage and show-jumping performance in competition of Dutch Warmblood horses. Livest Sci 107, 227-234

FN-German Equestrian Federation 2010. Annual report (2010) Warendorf, Germany

Groeneveld E, Kovač M, Mielenz N (2008) VCE User's Guide and Reference Manual Version 6.0. URL: ftp://ftp. tzv.fal.de/pub/latest_vce/doc/vce6-manual-3.1-A4.pdf [last accessed 06.06.2013]

Huizinga HA, Boukamp M, Smolders G (1990) Estimated parameters of field performance testing of mares from the Dutch Warmblood riding horse population. Livest Prod Sci 26, 291-299

Kearsley CGS, Woolliams JA, Coffey MP, Brotherstone S (2008) Use of competition data for genetic evaluations of eventing horses in Britain: Analysis of the dressage, showjumping and cross country phases of eventing competition. Livest Sci 118, 72-81

Kinghorn B, Kinghorn S (2006) Pedigree Viewer. Retrieved 24 October 2006, from http://www-personal.une. edu.au/ bkinghor/pedigree.htm [last accessed 04.06.2013

Koenen EPC, van Veldhuizen AE, Brascamp EW (1995) Genetic parameters of linear scored conformation traits and their relation to dressage and show-jumping performance in the Dutch Warmblood Riding Horse population. Livest Prod Sci 43, 85-94 
Kovač M, Groeneveld E (2003) VCE User's Guide and Reference Manual Version 5.1. Institute of Animal Husbandry and Animal Behavior, Federal Research Center of Agriculture, Mariensee, Germany

Lührs-Behnke H (2005) [Genetic analysis for traits of performance tests in German horse breeding]. Doctoral thesis. University Kiel [in German]

MacCluer JW, Boyce AJ, Dyke B, Weitkamp LR, Pfenning DW, Parsons CJ (1983) Inbreeding and pedigree structure in Standardbred horses. J Hered 74, 394-399

Patterson HD, Thompson R (1971) Recovery of inter-block information when block sizes are unequal. Biometrika 58, 545-554

Rekaya R, Weigel KA, Gianola D (2003) Bayesian Estimation of Parameters of a Structural Model for Genetic Covariances Between Milk Yield in Five Regions of the United States. J Dairy Sci 86, 1837-1844

Ruhlmann C, Bruns E, Fraehr E, Philipsson J, Janssens S, Quinn K, Thorén Hellsten E, Ricard A (2009) Genetic connectedness between seven European countries for performance in jumping competitions of warmblood riding horses. Livest Sci 120, 75-86

Rustin M, Janssens S, Buys N, Gengler N (2009) Multi-trait animal model estimation of genetic parameters for linear type and gait traits in the Belgian warmblood horse. J Anim Breed Genet 126, 378-386

Schade W (1996) [Development of an artificial insemination breeding program for the Hanoverian warmblood]. Doctoral thesis. University Göttingen, Germany [in German]

Teegen R (2008) [Analysis of a breeding program using the example of the Trakehner Breeding Association]. Doctoral thesis. University Kiel [in German]

Thorén Hellsten E, Jorjani H, Philipsson J (2008) Connectedness among five European sport horse populations. Livest Sci 118, 147-156

Thorén Hellsten E, Jorjani H, Philipsson J (2009) Genetic correlations between similar traits in the Danish and Swedish Warmblood sport horse populations. Livest Sci 124, 15-20

Thorén Hellsten E, Viklund Å, Koenen EPC, Ricard A, Bruns E, Philipsson J (2006) Review of genetic parameters estimated at stallion and young horse performance tests and their correlations with later results in dressage and show-jumping competition. Livest Sci 103, 1-12

Viklund Å, Braam Å, Näsholm A, Strandberg E, Philipsson J (2010) Genetic variation in competition traits at different ages and time periods and correlations with traits at field tests of 4 -year-old Swedish Warmblood horses. Animal 4, 682-691

Viklund Å, Thorén Hellsten E, Näsholm A, Strandberg E, Philipsson J (2008) Genetic parameters for traits evaluated at field tests of 3- and 4-year-old Swedish Warmblood horses. Animal 2, 1832-1841

von Velsen-Zerweck A (1998) [Integrated breeding value estimation for breeding horses]. Doctoral thesis. University Göttingen, Germany [in German]

Wallin L, Strandberg E, Philipsson J (2003) Genetic correlations between field test results of Swedish Warmblood Riding Horses as 4-year-olds and lifetime performance results in dressage and show jumping. Livest Prod Sci 82, 61-71

Weigel K, Rekaya R, Fikse F, Zwald N, Gianola D (2000) Data structure and connectedness issues in international dairy sire evaluations. In: Proceedings of the 2000 Interbull Meeting. 14-15 May 2000, Bled, Slovenia, Interbull Bulletin 25, 26-30

Willms F, Röhe R, Kalm E (1999) [Genetic analysis for traits from horse breeding considering pathologic changes in the limbs]. Züchtungskunde 66, 255-267 [in German] 